\title{
A 12-year high-resolution climatology of atmospheric water transport over the Tibetan Plateau
}

\author{
J. Curio ${ }^{1}$, F. Maussion ${ }^{1,2}$, and D. Scherer ${ }^{1}$ \\ ${ }^{1}$ Chair of Climatology, Technische Universität Berlin, Berlin, Germany \\ ${ }^{2}$ Institute of Meteorology and Geophysics, University of Innsbruck, Innsbruck, Austria \\ Correspondence to: J. Curio (julia.curio@tu-berlin.de) \\ Received: 7 September 2014 - Published in Earth Syst. Dynam. Discuss.: 2 October 2014 \\ Revised: 6 February 2015 - Accepted: 22 February 2015 - Published: 13 March 2015
}

\begin{abstract}
The Tibetan Plateau (TP) plays a key role in the water cycle of high Asia and its downstream regions. The respective influence of the Indian and East Asian summer monsoon on TP precipitation and regional water resources, together with the detection of moisture transport pathways and source regions are the subject of recent research. In this study, we present a 12-year high-resolution climatology of the atmospheric water transport (AWT) over and towards the TP using a new data set, the High Asia Refined analysis (HAR), which better represents the complex topography of the TP and surrounding high mountain ranges than coarse-resolution data sets. We focus on spatiotemporal patterns, vertical distribution and transport through the TP boundaries. The results show that the mid-latitude westerlies have a higher share in summertime AWT over the TP than assumed so far. Water vapour (WV) transport constitutes the main part, whereby transport of water as cloud particles (CP) also plays a role in winter in the Karakoram and western Himalayan regions. High mountain valleys in the Himalayas facilitate AWT from the south, whereas the high mountain regions inhibit AWT to a large extent and limit the influence of the Indian summer monsoon. No transport from the East Asian monsoon to the TP could be detected. Our results show that $36.8 \pm 6.3 \%$ of the atmospheric moisture needed for precipitation comes from outside the TP, while the remaining $63.2 \%$ is provided by local moisture recycling.
\end{abstract}

\section{Introduction}

The Tibetan Plateau (TP) is often referred to as the "world water tower" (Xu et al., 2008), as it is the source of many large Asian rivers such as the Indus, Ganges, Brahmaputra, Yellow River, Yangtze and Mekong. The TP is one of the most active centres in the word water cycle and constitutes an essential source of moisture for the downstream regions in East Asia (Immerzeel et al., 2010). The transport of moisture to the TP is crucial for a sustainable water supply in the downstream regions like the Yellow and Yangtze river valleys (Zhang et al., 2013). Moisture transport in and to the TP is influenced by mesoscale features (Sugimoto et al., 2008), but it is also driven by large-scale atmospheric circulation, most notably the monsoon systems (Webster et al., 1998) and the mid-latitude westerlies (Schiemann et al., 2009). The unique topography of the TP, with its large extent and an average altitude of more than $4000 \mathrm{~m}$ makes it of particular interest because of its interaction with large-scale circulation. The surrounding high mountain ranges, Himalaya, Karakoram, Pamir, Tien Shan and Kunlun Shan, act as a barrier for the atmospheric moisture transport.

During the last few decades the TP experienced climate changes of warmer and wetter conditions (Yang et al., 2011, 2014), which have a direct impact on the hydrological cycle. Precipitable water (PW) shows increasing trends in the eastern and western TP and decreasing trends in the central TP for the relatively short period of 2000-2010 (Lu et al., 2014). The poleward shift of the East Asian westerly jet in the period 1979-2011 and the assumed intensification of the monsoon system under climate change conditions (while Yao et al., 2012, described a recent weakening of the Indian summer monsoon) are supposed to cause large areas of the TP to become wetter (Gao et al., 2014). Lake expansion in the central TP has intensified during the last few decades, due 
to global warming and its effects on the hydrological cycle of the TP (e.g. glacier retreat, permafrost degradation; Liu et al., 2010). The additional water vapour (WV), necessary for lake expansion, is assumed to come from outside the TP and therefore it is important for better understanding the WV sources and transport processes (Yang et al., 2014).

Many studies on atmospheric water transport (AWT) in and to the TP focus on the question of how the Indian and East Asian summer monsoon systems affect precipitation on the Tibetan Plateau, and how changes of the monsoonal circulation impact local and regional water resources (Gao et al., 2014; Immerzeel et al., 2013; Simmonds et al., 1999). Yao et al. (2012) and Bolch et al. (2012) list the Indian monsoon, the mid-latitude westerlies and the East Asian monsoon as drivers of climate variability in the TP. In previous studies, the influence of the westerlies and the monsoon system was examined on the basis of the precipitation timing and so is supposed to be limited to winter (westerlies) or summer (Indian and East Asian summer monsoon) (e.g. Hren et al., 2009; Tian et al., 2007; Yang et al., 2014). The origin of the atmospheric moisture over the TP plays a key role in recent research (e.g. Chen et al., 2012; Feng and Zhou, 2012). Their are three sources of moisture entering the TP: the Asian monsoon systems, the mid-latitude westerlies, and local moisture recycling. The general assumption is that the main WV source for summer precipitation in the TP is the Indian summer monsoon. Pathways for the moisture originating in the Arabian Sea, the Bay of Bengal and the westerlies are high mountain valleys in the southern and western border of the TP, e.g. the Brahmaputra Channel in the easternmost part of the Himalayas and the meridionally orientated valley in the central and western parts.

One method to identify the sources of moisture is to analyse the isotopic composition of precipitation, e.g. observed and modelled stable oxygen isotope ratios $\left(\delta^{18} \mathrm{O}\right)$ and hydrogen isotope values $(\delta \mathrm{D})$ (Araguás-Araguás et al., 1998; Tian et al., 2007; Yao et al., 2013) and the isotopic composition of the water in rivers and smaller water streams (Hren et al., 2009) and of climate proxies such as ice and sediment cores (Kang et al., 2007; Günther et al., 2011; An et al., 2012; Guenther et al., 2013; Joswiak et al., 2013). The latter ones can be used to analyse the moisture transport/conditions on the plateau and its source regions in the past. An et al. (2012) analysed a sediment core from Lake Qinghai in the north-east of the TP that reaches back $32 \mathrm{ka}$. They focused on the interplay of the westerlies and the Asian monsoon and showed that there is an anti-phase relationship with periods of dominant westerlies and periods with dominant Asian monsoon. Higher monsoon activity during the current warming period is found by studying variations in the monsoon intensity in the TP during the last 1000 years using data from sediment and ice cores (Günther et al., 2011). A shift in the isotope signals implies that the contribution of westerly moisture to the ice-core accumulation was relatively greater before the 1940s (Joswiak et al., 2013).
For the present-day conditions, various studies produce different results. Both the southern Indian Ocean (Indian summer monsoon) (Yao et al., 2013) and the Pacific Ocean (East Asian Monsoon) (Araguás-Araguás et al., 1998) are identified as the dominant moisture sources for summer precipitation in the TP. The analysis of stable isotopes of precipitation samples in western China show that the southern TP receives monsoon moisture in summer and westerly moisture in winter, while the moisture in western TP is delivered by the south-west monsoon (Tian et al., 2007). Hren et al. (2009), who sampled 191 stream waters across the TP and the Himalaya, found that the moisture entering the southeastern TP through the Brahmaputra Channel originates in the Bay of Bengal. This monsoonal moisture is mixed with central Asian air masses the farther west and north in the TP the sampling site is located. The role of local moisture recycling as an additionally moisture source is also emphasized in many studies (e.g. Joswiak et al., 2013; Kurita and Yamada, 2008; Trenberth, 1999). Araguás-Araguás et al. (1998) found that it is dominant in winter and spring.

Another method to investigate the moisture transport in the TP is gridded atmospheric data sets, for example global reanalysis data, regional atmospheric models and remote sensing data. Chen et al. (2012) used backward and forward trajectories to identify the sources and sinks of moisture for the TP in summer. Their results show that for periods longer than 4 days backwards, the main moisture source is the Arabian Sea, while for shorter periods, the Bay of Bengal, the Arabian Sea and the north-western part of the TP contribute moisture in the same order of magnitude. The results from the forward tracking underline the relevance of the TP moisture for the precipitation in East Asia. Feng and Zhou (2012) found that the main WV transport for summer precipitation takes place through the southern border of the TP and originates in the Bay of Bengal and the Indian Ocean. They also point out that the southern branch of the mid-latitude westerlies transports moisture to the TP too, but its share is distinctly lower. Lu et al. (2014) analysed the atmospheric conditions and pathways of moisture to the TP for a wet and dry monsoon season and showed that differences in the atmospheric circulation have a direct impact on the moisture transport and on the PW over the TP. Meridionally orientated high mountain valleys in the Himalayas can channel water vapour and precipitation to the TP (Bookhagen and Burbank, 2010).

Previous studies relied on global reanalysis data sets to quantify the transport to the TP. Recently, a new highresolution data set, the High Asia Refined analysis (HAR; Maussion et al., 2014), was made available. With a high spatial $(30$ and $10 \mathrm{~km})$ and temporal $(3$ and $1 \mathrm{~h})$ resolution, the data set allows us to analyse the AWT above the Tibetan Plateau differentiated in space and time. By using this new data set with a distinctly higher horizontal resolution than the global data sets, the question arises of whether or not the more realistic representation of the topography of the TP and 
the surrounding high mountain ranges leads to an improvement in atmospheric moisture representation.

The objectives of the current study are threefold:

i. describe the characteristics of AWT over and to the TP as resolved by the HAR data set during the last decade, with focus on spatial patterns, seasonal evolution and vertical distribution,

ii. examine the barrier effect of the topography on AWT and detect the major transport channels to the plateau,

iii. and quantify the importance of increasing model spatial resolution on these transport channels.

Here we present a 12-year climatology of atmospheric water transport (AWT) over the TP and adjacent mountain ranges based on the HAR. We focus on the period 2001-2012 (referred to the "last decade" for convenience). First, we will look at the mean annual cycle of AWT (water vapour and cloud particles) to detect the mean patterns and transport channels. The vertical distribution of the transport is then analysed using selected model levels. We also compute vertical cross sections along the border of the TP to quantify the atmospheric water input and verify the importance of the detected transport channels. In the final step, we provide an estimation of the budget of AWT and its share of the precipitation falling on the TP.

\section{Data and methods}

\subsection{The HAR data set}

We use meteorological fields provided by the High Asia Refined analysis (HAR). The HAR is the result of the dynamical downscaling of the global gridded data set, the Operational Model Global Tropospheric Analyses (final analyses, FNL; data set ds083.2). These final analyses are available every $6 \mathrm{~h}$ and have a spatial resolution of $1^{\circ}$. The model used for this purpose is the advanced research version of the Weather and Research Forecasting model (WRF-ARW, Skamarock and Klemp, 2008) version 3.3.1. The HAR provides products at a spatial resolution of $30 \mathrm{~km}$ and temporal resolution of $3 \mathrm{~h}$ for the first domain, covering most parts of central Asia (HAR30). A second nested domain (HAR10) covers high Asia and the TP with a spatial resolution of $10 \mathrm{~km}$ and temporal resolution of $1 \mathrm{~h}$ (Fig. 1). The data set is available online at http://www.klima.tu-berlin.de/HAR and described in detail by Maussion et al. $(2011,2014)$. The HAR provides meteorological fields at the surface and on 28 terrainfollowing vertical sigma levels. The data set covers a period of more than 12 years from October 2000 to December 2012 and is updated continuously. HAR products are available for different time aggregation levels: hourly (original temporal model resolution), daily, monthly and yearly.

The HAR precipitation data were compared to rain gauge observation and precipitation estimates from the Tropi- cal Rainfall Measuring Mission (TRMM) by Maussion et al. (2011, 2014). The accuracy of the precipitation data is described more in detail in Sect. 4.2.

\subsection{Moisture transport}

Atmospheric water transport happens through WV transport and as cloud particle (CP) transport. In this study, we are interested in cloud particle transport but do not further distinguish between liquid (water droplets) and solid (ice) cloud particles which are both resolved by the model microphysics. WV and CP fluxes are calculated for each of the 28 original sigma levels, which are terrain following, based on the original temporal model resolution of $1 \mathrm{~h}$ (HAR10) and $3 \mathrm{~h}$ (HAR30) using the formula

$Q=v_{\mathrm{h}} \rho q \Delta z$

where $Q$ is the water vapour flux $\left(\mathrm{kg} \mathrm{m}^{-1} \mathrm{~s}^{-1}\right)$ or cloud particle flux, $v_{\mathrm{h}}$ denotes the horizontal wind vector $\left(\mathrm{m} \mathrm{s}^{-1}\right), \rho$ is the dry air density $\left(\mathrm{kg} \mathrm{m}^{-3}\right)$ and $q$ is the specific humidity $\left(\mathrm{kg} \mathrm{kg}^{-1}\right) . \Delta z$ is the thickness of each sigma level (m), this value is not constant but increases with increasing height above ground. Since the WRF model just provides mixing ratios $(r)$ for the three atmospheric water components (water vapour, liquid water and ice), we first calculated the specific humidity for each component using the relationship

$q=\frac{r}{(1+r)}$

Additionally, we integrated the fluxes over the whole atmospheric column to obtain the vertically integrated atmospheric water transport fluxes. The vertical integration is performed along the metric $z$ coordinate along the model sigma levels from surface to top using the rectangle method.

$Q=\int_{z=z_{\mathrm{sfc}}}^{z=z_{\text {top }}} v_{\mathrm{h}} \rho q \Delta z$

We calculated these fluxes for the original model levels and did not interpolate them to pressure levels to avoid information loss due to the interpolation. For the analyses, 10 and 5 grid points from the HAR30 and HAR10 domain boundaries, respectively, are removed to avoid lateral boundary effects.

To analyse the AWT towards the TP, we compute vertical cross sections along transects following the border of the TP. To be able to calculate a moisture budget, we defined a region which we henceforth call "the inner TP", with 14 transects attempting to follow the highest elevations in the mountain ranges and to cut across the high mountain valleys which we assume to be pathways for atmospheric moisture. A map with the transects is shown in Fig. 1. The $u$ and $v$ components of AWT are then rotated to the transect coordinate system to compute the normal fluxes towards the cross section. 

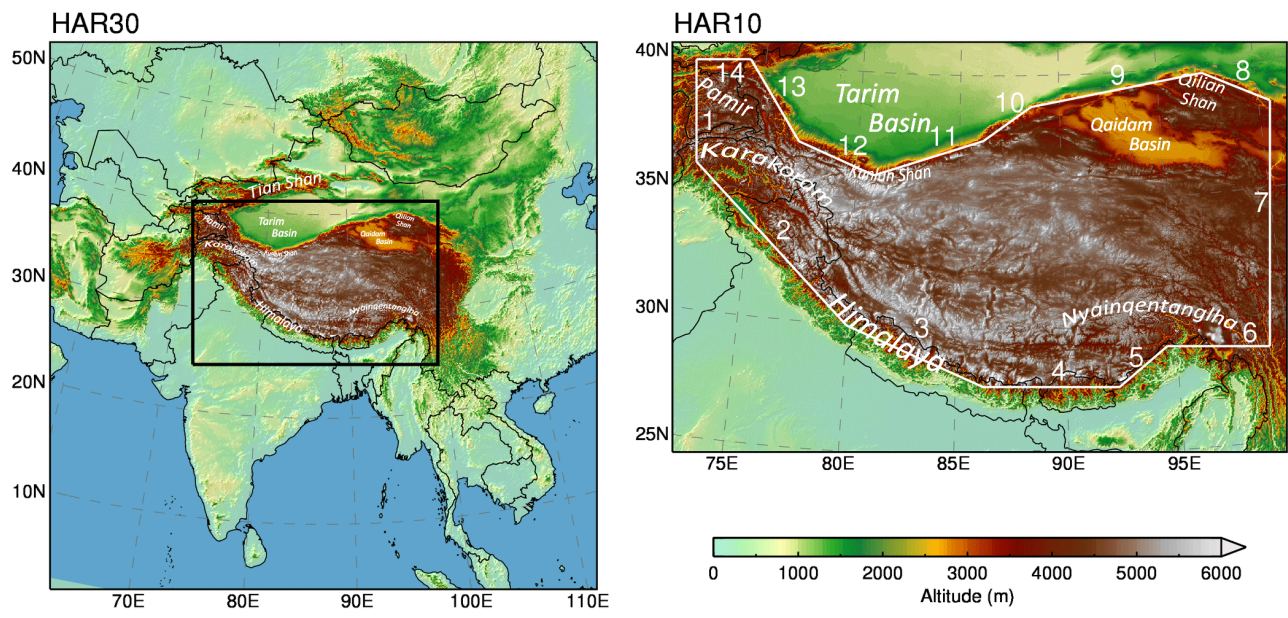

Figure 1. Maps of the Weather and Research Forecasting (WRF) model domains HAR30 (south-central Asia domain, $30 \mathrm{~km}$ resolution) and HAR10 (high Asia domain, $10 \mathrm{~km}$ resolution). The transects surrounding the Tibetan Plateau (numbered 1-14) are drawn in white. The region within the defined boundaries is called "inner TP" throughout the manuscript. Geographical locations are indicated (modified after Maussion et al., 2014).

\subsection{ERA-Interim}

To examine if our data set is able to reproduce the general characteristics of the WV flux, we compare the WV fluxes derived from HAR30 with ERA-Interim Reanalysis data (Dee et al., 2011). The ERA-Interim WV fluxes are available online as an integral over the atmospheric column for the eastward $(u)$ and northward $(v)$ components as monthly means. ERA-Interim has a horizontal resolution of $0.75^{\circ}$. To calculate the differences between the HAR30 and ERA-Interim WV fluxes, we transformed HAR30 data to the ERA-Interim grid by averaging the HAR30 grid points below each ERA-Interim grid point. The $u$ and $v$ components of the HAR fluxes were rotated to Earth coordinates first.

\section{Results}

\subsection{Comparison of HAR30 and ERA-Interim water vapour fluxes}

The general patterns and the magnitude of the WV transport amounts of HAR30 and ERA-Interim are in agreement (Fig. 2). Figure 2c shows the differences between HAR30 and ERA-Interim for July when the largest differences were found. The main differences between the two data sets are visible south of the eastern and central Tibetan Plateau along the southern slopes of the Himalayas. The WV transport through the Brahmaputra Channel towards the Tibetan Plateau is higher for ERA-Interim than for HAR30. This is probably due to differences in the representation of the orography, caused by different horizontal resolutions. HAR30 produces more transport westward along the Himalayas (upstream Ganges River), which is caused by more WV blockage. When the WV flux hits the Himalayas from the south it is mostly redirected to the west and follows the southern slopes of the Himalayas. Additionally there are differences in the Arabian Sea and the Bay of Bengal. Over the Arabian Sea, more water vapour is transported further to the south in the HAR30 data set. The transport direction in the ERAInterim data set is more from the south-west to north-east. Therefore, the transport amount over the southern part of the Indian peninsula is also higher for HAR30. Because of that southward shift, the transport amount over the southern part of the Bay of Bengal is higher for HAR30 than for ERAInterim and thus has a stronger northward component in the eastern part of the bay. So the South Asian Monsoon circulation has a modified shape in the HAR, possibly due to the influence of the southern branch of the mid-latitude westerlies which is more pronounced in HAR30. In winter, the differences are in general less pronounced (not shown).

\subsection{Climatology of the atmospheric water transport (AWT)}

Figure 3 displays the December-February (DJF) (left) and June-August (JJA) (right) decadal average of the vertically integrated atmospheric water transport (AWT) derived from HAR30. In winter (DJF), the AWT from west to east is dominant over the TP and most parts of high Asia. In the tropical ocean region, there is transport from east to west with the trade winds. The TP and the regions north of the plateau show small transport amounts, below $40 \mathrm{~kg} \mathrm{~m}^{-1} \mathrm{~s}^{-1}$. For comparison, AWT reaches up to $450 \mathrm{~kg} \mathrm{~m}^{-1} \mathrm{~s}^{-1}$ over the South Chinese Sea off the coast of Vietnam. In summer (JJA), the pattern in the southern part of the domain is completely different from winter due to the circulation change related to the Indian summer monsoon (ISM). The largest amount of atmospheric water is now transported from west to east over the 
(a)

HAR30
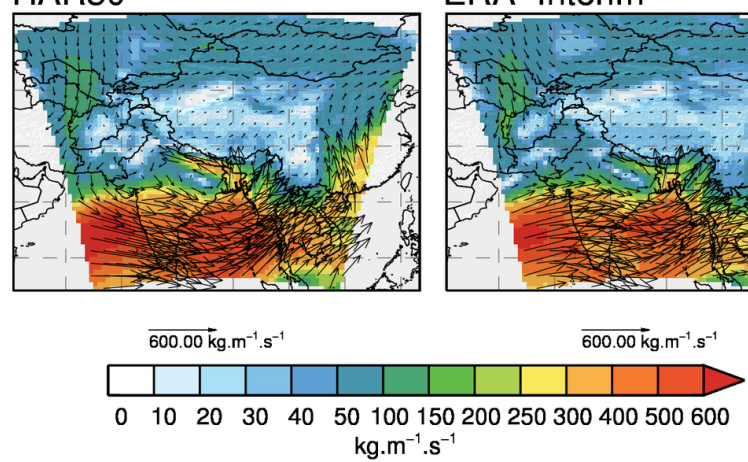

(c)

HAR30 - ERA-Interim

ERA-Interim

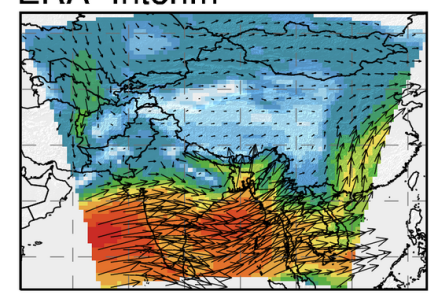

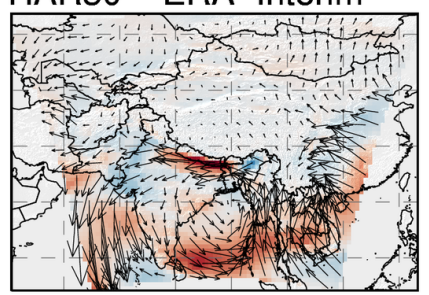

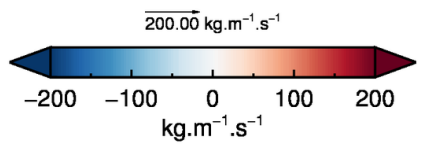

Figure 2. Decadal average of the vertically integrated water vapour flux $\left(\mathrm{kg} \mathrm{m}^{-1} \mathrm{~s}^{-1}\right)$ in July for HAR30 (a), ERA-Interim (b) and their difference (c). The grid points without HAR30 data are masked out. Colour shading denotes strength of water vapour flux, arrows (plotted every second grid point) indicate transport direction (length of arrows is proportional to flux strength up to $600 \mathrm{~kg} \mathrm{~m}^{-1} \mathrm{~s}^{-1}$ for (a) and (b) and up to $200 \mathrm{~kg} \mathrm{~m}^{-1} \mathrm{~s}^{-1}$ for (c) and is constant afterwards for more readability).
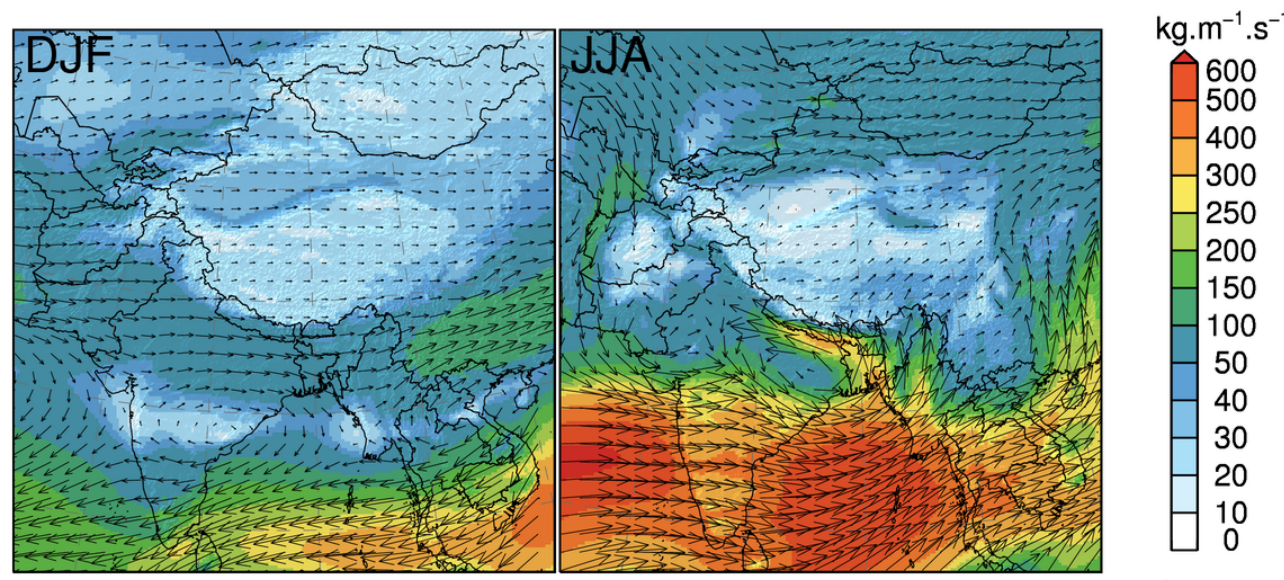

$\overline{200.00} \mathrm{~kg} \cdot \mathrm{m}^{-1} \cdot \mathrm{s}^{-1}$

Figure 3. Decadal average of the vertically integrated water vapour flux $\left(\mathrm{kg} \mathrm{m}^{-1} \mathrm{~s}^{-1}\right)$ in DJF (left) and JJA (right) for HAR30. Colour shading denotes strength of water vapour flux, arrows (plotted every sixth grid point) indicate transport direction (length of arrows is proportional to flux strength up to $200 \mathrm{~kg} \mathrm{~m}^{-1} \mathrm{~s}^{-1}$ and is constant afterwards for more readability).

Arabian Sea and the Bay of Bengal. Over the Bay of Bengal the flow gets a larger southerly component, and atmospheric water is directly transported to the southern slopes of the Himalayas. Over the TP the transport amount is still low in comparison.

\subsubsection{Annual cycle of HAR10 water vapour (WV) transport}

The annual cycle of vertically integrated WV transport (monthly decadal average) is provided in Fig. 4, and the WV transport spatially averaged for the inner TP is shown in Fig. 5. In winter, the westerlies are dominant in the whole domain, and therefore the available $\mathrm{WV}$ is transported eastward. The highest amounts of WV transport $\left(50-200 \mathrm{~kg} \mathrm{~m}^{-1} \mathrm{~s}^{-1}\right)$ occur south of the Himalayas. Over the TP, the WV transport amount is distinctly lower (10$50 \mathrm{~kg} \mathrm{~m}^{-1} \mathrm{~s}^{-1}$ ). The WV transport towards the TP can only take place through some high mountain valleys at the southwestern border of the TP (western Himalayas, Karakoram, Pamir) and in the south-east of the TP where the Brahmaputra Channel is located. Additionally, the atmosphere over the TP is cold in winter and cannot hold large amounts of WV. The transport of WV over the TP further to the east is facilitated by lower elevated west-east orientated regions like the Yarlung Tsangpo (Brahmaputra) River course in the south. Therefore, the highest transport amounts are visible in the south-eastern and central southern TP.

From May to July the amount of transported WV in these regions increases and the region with higher transport extends to the central TP. This intensification of the transport is also visible in Fig. 5a and takes place before the actual mon- 

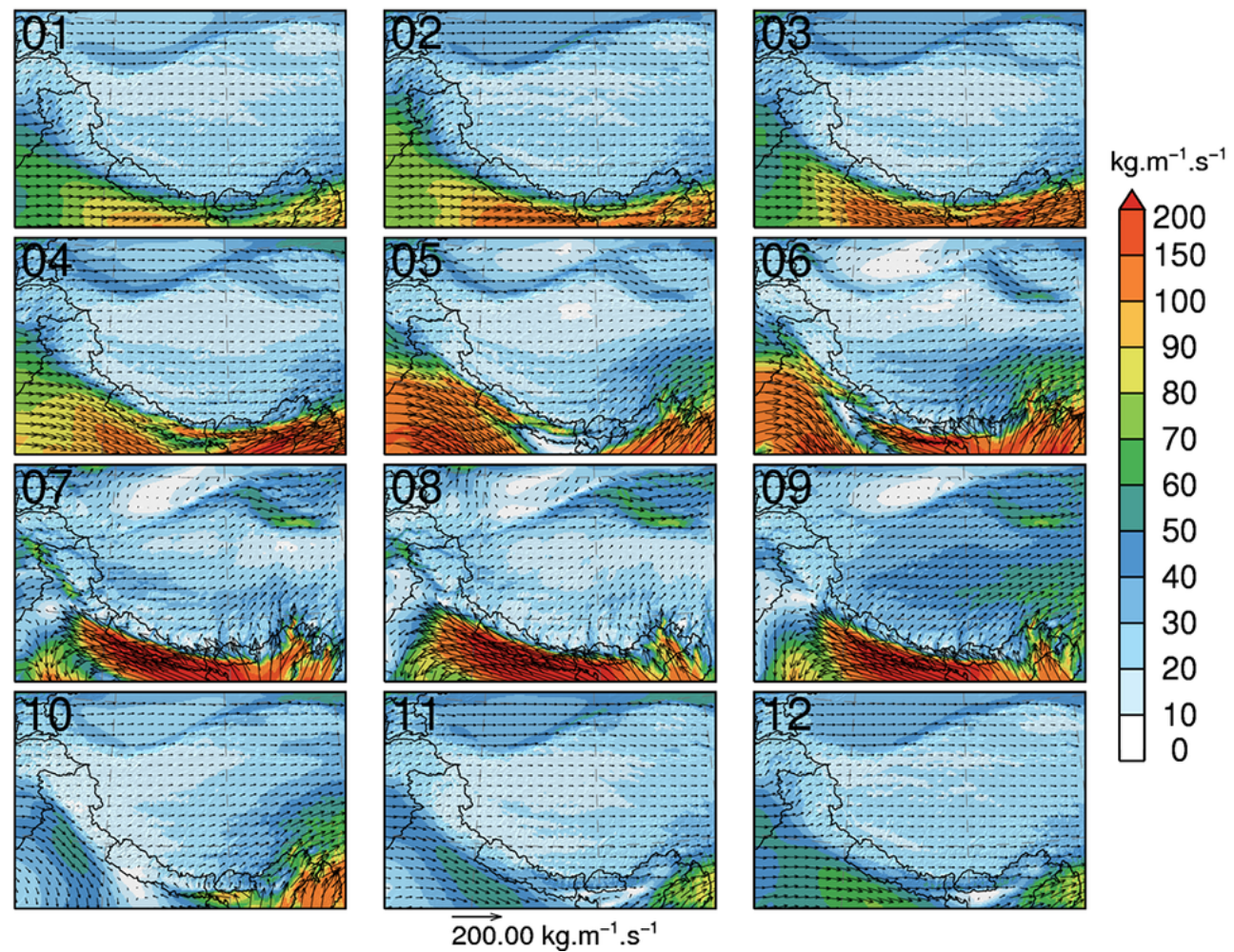

Figure 4. Decadal average of the vertically integrated water vapour flux $\left(\mathrm{kg} \mathrm{m}^{-1} \mathrm{~s}^{-1}\right)$ in every month for HAR10. Colour shading denotes strength of water vapour flux, arrows (plotted every eighth grid point) indicate transport direction (length of arrows is proportional to flux strength up to $200 \mathrm{~kg} \mathrm{~m}^{-1} \mathrm{~s}^{-1}$ and is constant afterwards for more readability).

(a)

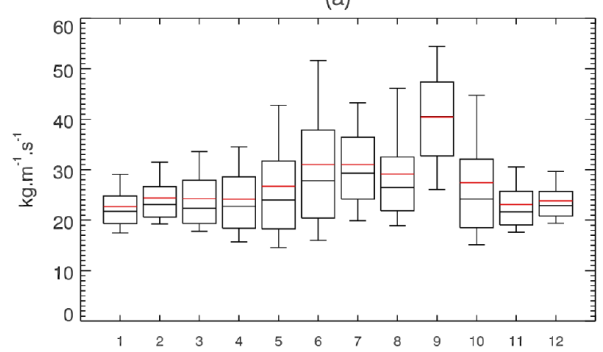

(b)

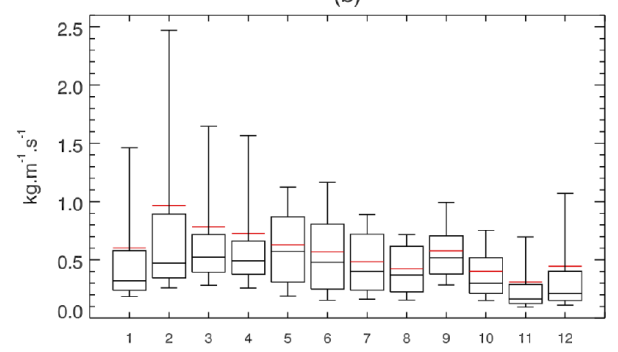

Figure 5. Box plots of the decadal average of the vertically integrated water vapour flux (a) and cloud particle flux (b) on the inner TP for HAR10 $\left(\mathrm{kg} \mathrm{m}^{-1} \mathrm{~s}^{-1}\right)$. The boxes represent the range from the 25 th to the 75 th percentile. The boxes are divided by the median value (black) and the mean value (red). The whiskers represent the 10th and the 90th percentile, respectively. Note the different scales of the $y$ axes.

soon season. Already by May, the WV flux south-east of the Himalayas obtains a more southerly component and the WV is no longer transported along the southern slopes, instead hitting the mountain ranges from the south. This results in an increase of the AWT amount north of the Himalayas. Due to the further evolution of the Indian summer monsoon, the transport intensifies over summer. However, large amounts of AWT from the Bay of Bengal northward to the Himalayas are blocked by the orographic barrier and redirected westward. This leads to high amounts of WV transport along the southern slopes of the Himalayas following the Ganges River course to the west. WV transport to the TP is possible where meridionally orientated valleys along this course exist.

The WV transport through the south-western border of the TP also increases over summer. This WV is not transported towards the TP by the monsoonal flow, but is rather provided by the southern branch of the mid-latitude westerlies. This is clearly visible in the transport patterns of the HAR30 domain (Fig. 3). Another hint for the contribution of the westerlies to the $\mathrm{WV}$ transport over the TP is the dominant transport direction in the southern TP from west to east. This eastward transport starts further west than the monsoonal flow reaches 
along the southern slopes. So the WV from the Bay of Bengal cannot be the major source of the moisture transported in the westernmost regions of the TP.

In summer, the WV transport over the Qaidam Basin from north-west southward is nearly as high as in the monsoonal affected south-east of the TP. Figure 6, representing the decadal monthly average of HAR10 precipitation, shows a precipitation minimum in this region in summer, although large amounts of WV are transported to this region. Convection might be hindered by subsidence or high wind speeds (wind shear effect).

In September, we find the highest WV transport amounts over the TP. This intensification of the water vapour transport occurs because the precipitation in September (Fig. 6) is low compared to the summer months. The surface is wet due to the high precipitation rates in July and August and the temperatures are still relatively high, leading to high evaporation from the land surface. The evaporated moisture can be transported away from the source region and will not be rained out over the TP. Another reason for higher transport amounts is the wind speed recovery after the withdraw of the monsoon, which is visible in the $500 \mathrm{hPa}$ wind field (Maussion et al., 2014), and facilitates higher evaporation rates and therefore higher transport amounts. In October there is only transport to the TP in the eastern and central parts of the Himalayas, because the monsoon circulation weakens and the fluxes do not reach as far westward into the Ganges valley as before. The flux from the westerlies reaches far more to the east along the southern slopes of the Himalayas (TP). In November, this pattern becomes more intense, there is no westward flux south of the Himalayas visible, the monsoon circulation collapses and wintertime conditions are established.

\subsubsection{HAR10 cloud particle (CP) transport}

The median value of HAR10 WV transport for the inner TP is between 20 and $40 \mathrm{~kg} \mathrm{~m}^{-1} \mathrm{~s}^{-1}$ over the whole year, while it is between 0.2 and $0.6 \mathrm{~kg} \mathrm{~m}^{-1} \mathrm{~s}^{-1}$ for the CP transport (Fig. 5). Differences in the annual cycle of the two components are clearly visible: the WV transport has its peak in summer and the CP transport in winter. To examine the relevance of $\mathrm{CP}$ transport for AWT, we looked at the transport patterns and amounts and calculated the contribution of the CP flux to AWT as a monthly decadal average in January and in July (Fig. 7). It shows that in winter in the Karakoram/Pamir/western Himalayas region, the CP flux can account for up to $25 \%$ of the entire AWT. This pattern matches with the wintertime precipitation pattern in this region (Fig. 6). From April on (not shown), we find relatively high transport amounts (up to $2-3 \mathrm{~kg} \mathrm{~m}^{-1} \mathrm{~s}^{-1}$ ) in the southeast of the domain, but in summer the $\mathrm{CP}$ transport amount decreases in these two regions to very small values. Just over the central eastern parts of the plateau the amount increases to around $8 \%$ of AWT. The percentage of CP in AWT is higher at higher elevations where the WV transport is lower because of lower temperatures. The relatively high percentage values over the Tarim Basin are related to the low AWT in general in this region

\subsection{Vertical structure of the atmospheric water transport}

We display the decadal average of AWT for selected vertical levels in Fig. 8. We selected the levels $1(\sim 25 \mathrm{~m}$ above ground in Tibet), 5 ( $\sim 450 \mathrm{~m}$ above ground in Tibet), $8(\sim 1200 \mathrm{~m}$ above ground in Tibet), $10(\sim 2200 \mathrm{~m}$ above ground in Tibet), $12(\sim 3200 \mathrm{~m}$ above ground in Tibet) and $15(\sim 5500 \mathrm{~m}$ above ground in Tibet) because these levels show the most interesting features of the WV transport. The WV transport near the ground (level 1) is generally low in the TP and just a little bit higher south of the Himalayas, probably because of the lower surface wind speeds and of the stronger mixing in the boundary layer. The transport amount increases strongly up to level 12 , where the largest transport occurs, due to higher wind speeds, higher moisture availability or both. Above this level, the WV transport starts to decrease and above level 17 (not shown) the transport amount is close to zero.

The general atmospheric circulation at different levels is visible in the transport patterns, but we have to consider that AWT is a complex mixture of wind and moisture availability. At the lower levels ( 1 and 5) we see the cyclonic circulation around the Tibetan heat low, with its centre in the central TP. At level 8, this structure shifts to the central northern TP. Level 12 and 15 (and levels in between) show an anticyclonic circulation around a centre in the southern TP, directly north of the Himalayas. This is the high-tropospheric Tibetan anticyclone that forms during May or early June (Flohn, 1968). In level 15 and 16, a second anticyclonic circulation is visible in the south-east of the domain, directly south of the Himalayas. Above these levels the anticyclonic circulation slowly weakens and a division into a northern part with transport from west to east, where the westerlies are dominant, and a southern part with transport from east to west is visible. Level 10, which lays between the cyclonic (level 1 and 5) and anticyclonic (level 12 and 15) circulation features, could be called the equilibrium level.

At level 5, monsoonal air and moisture is transported relatively far to the western (north-western) parts of the TP. Air from the south which originates in the tropical oceans (Indian summer monsoon) is included in the cyclonic circulation over the TP, but the WV does not seem to originate from the East Asian monsoon. In the higher levels (10-15), this cyclonic circulation is replaced by the westerlies and therefore extra-tropical air masses are transported to this region. Therefore, we find air masses and consequently moisture from different sources at one place. These results should be considered for the analysis of stable oxygen isotopes in precipitation samples, lake water, sediment and ice cores. Precipitation originating in the boundary layer will result in a monsoonal signal in the isotopes while precipitation originating 

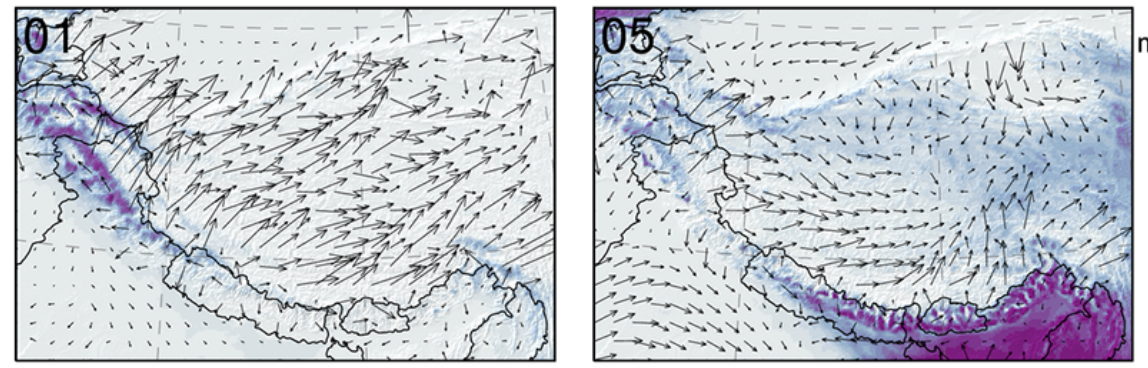

mm.month ${ }^{-1}$
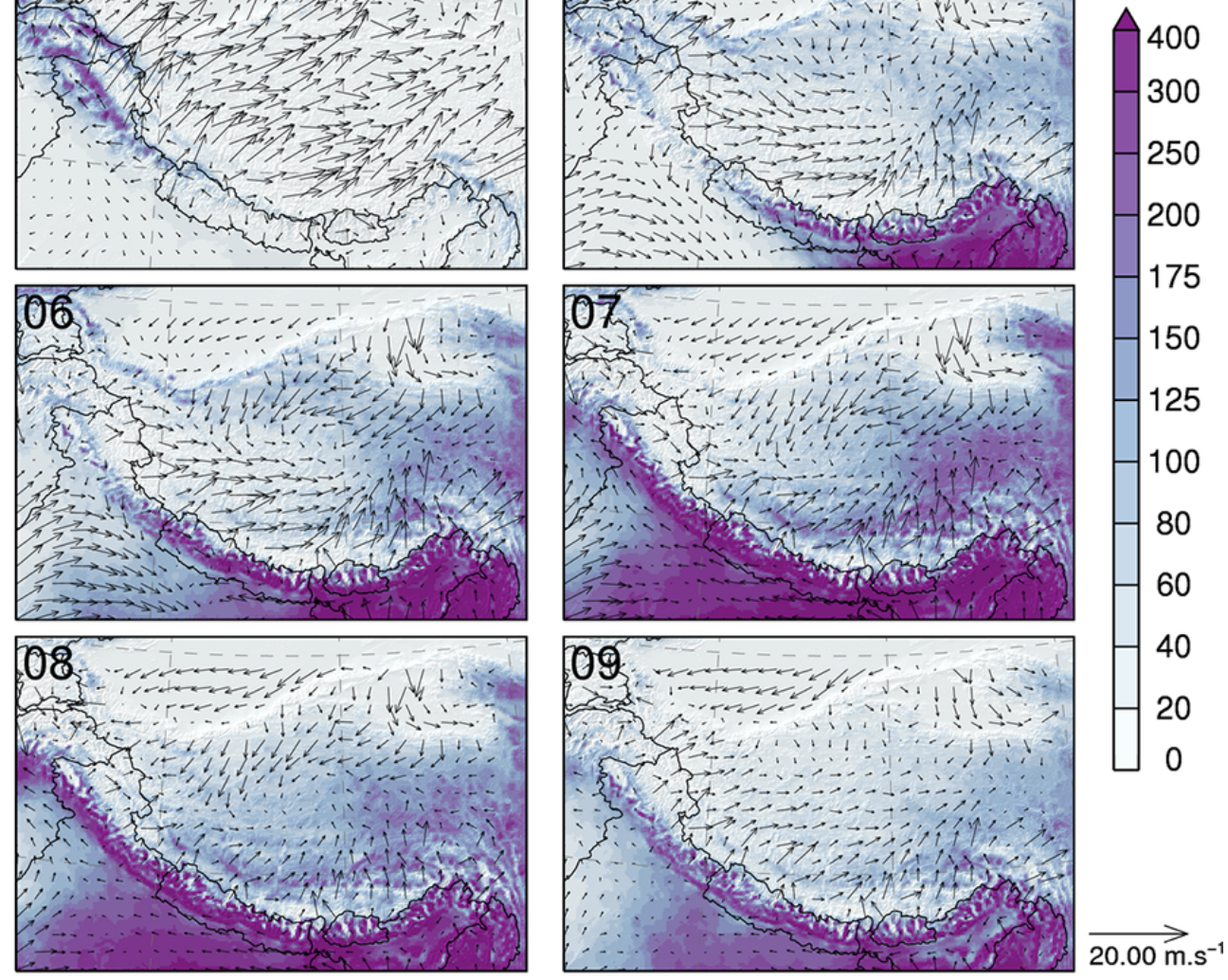

Figure 6. Decadal average of precipitation (mm month ${ }^{-1}$ ) in January (01), May (05), June (06), July (07), August (08), and September (09) for HAR10. The arrows show the $10 \mathrm{~m}$ wind field (every ninth grid point plotted).

(a)

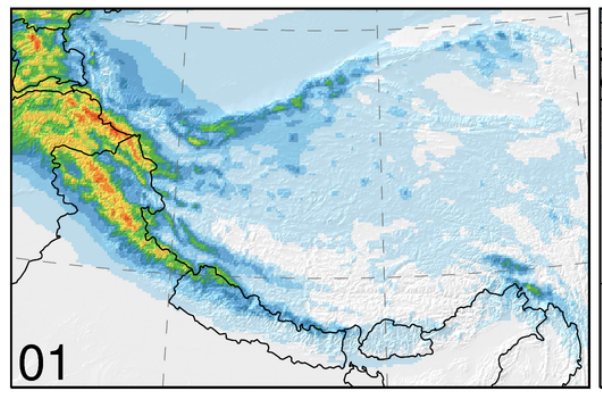

(b)

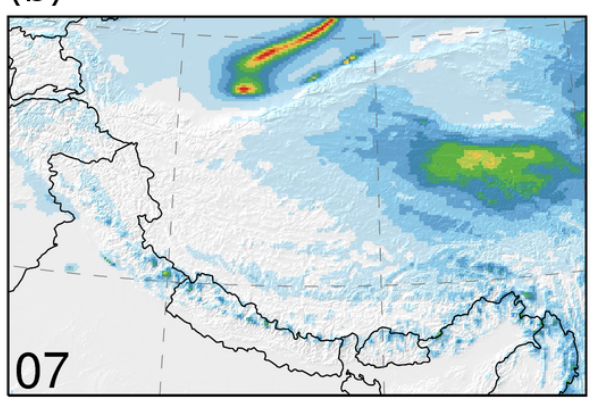

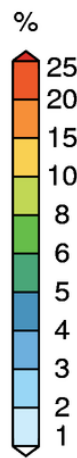

Figure 7. Decadal average of the contribution (\%) of cloud particle flux to atmospheric water transport in January (01, (a)) and July (07, (b)) for HAR10.

from deep convection could have an isotope signature dedicated to the westerlies.

In the dry Tarim Basin north of the TP, we can see an anticyclonic circulation above the boundary layer at level 10 and transport of WV from north-east to south-west following the northern boundary of the TP. Therefore, the air at this level tends to descend. This means that just below this level clouds in the boundary layer are possible. These clouds can only provide small amounts of precipitation due to their low vertical extent. Above this level, the transport of $\mathrm{WV}$ is admittedly higher and in the opposing direction, but does not result in precipitation. Deep convection is inhibited by the subsidence tendency at the lower level.

In the south-western parts of the domain, in the border region between India and Pakistan, we can see the same feature, but there it leads to higher differences in the precip- 

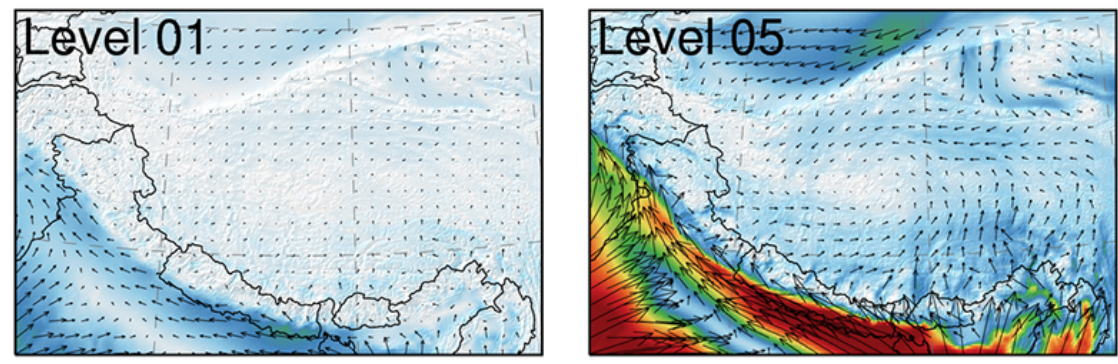

$\mathrm{kg} \cdot \mathrm{m}^{-1} \cdot \mathrm{s}^{-1}$
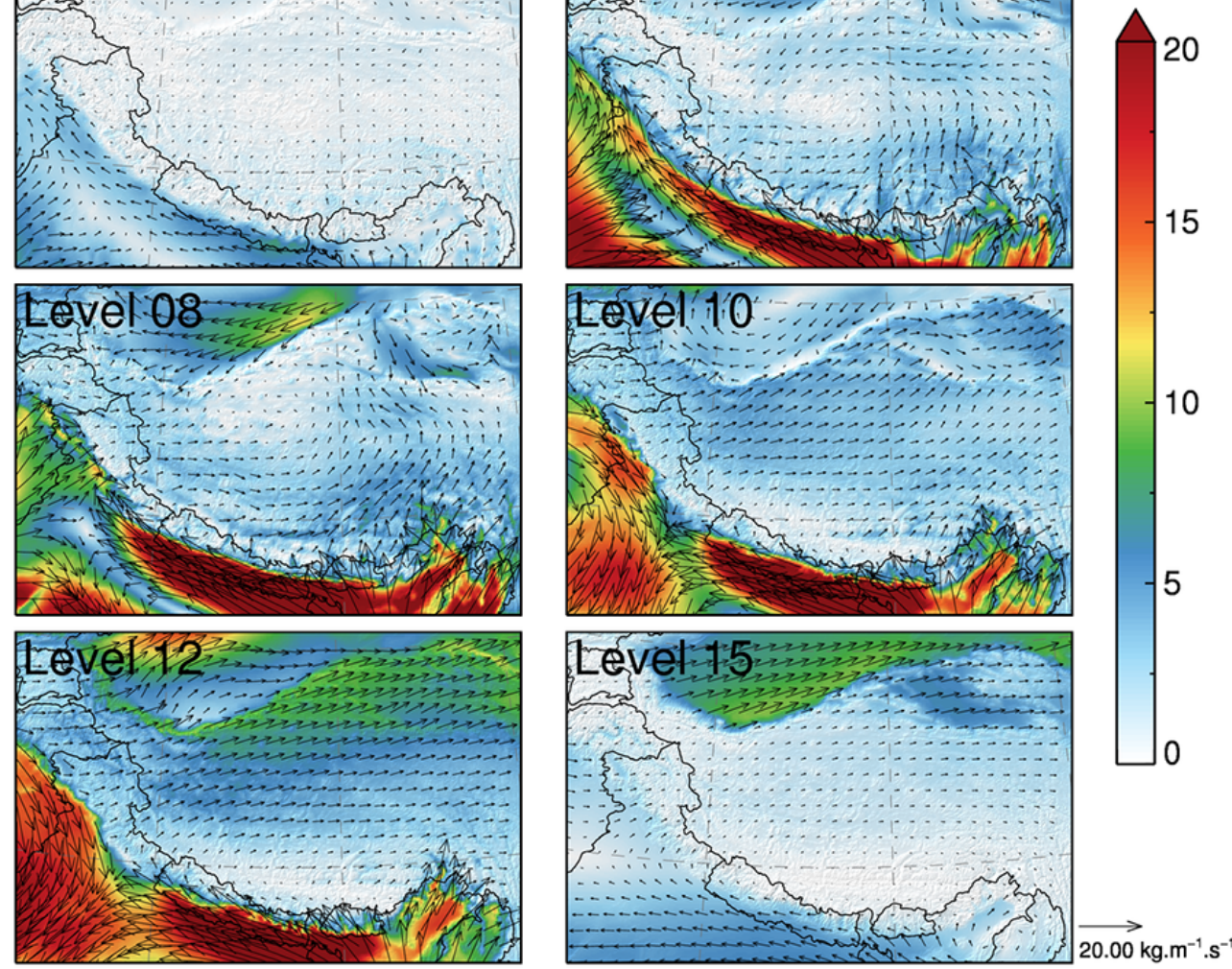

Figure 8. Decadal average of the water vapour flux $\left(\mathrm{kg} \mathrm{m}^{-1} \mathrm{~s}^{-1}\right)$ for single selected model levels $(1(\sim 25 \mathrm{~m}$ above ground in Tibet), 5 ( $\sim 450 \mathrm{~m}$ above ground in Tibet), 8 ( $\sim 1200 \mathrm{~m}$ above ground in Tibet), $10(\sim 2200 \mathrm{~m}$ above ground in Tibet), $12(\sim 3200 \mathrm{~m}$ above ground in Tibet) and $15(\sim 5500 \mathrm{~m}$ above ground in Tibet $))$ in July for HAR10. Colour shading denotes strength of water vapour flux, arrows (plotted every eighth grid point) indicate transport direction (length of arrows is proportional to flux strength up to $20 \mathrm{~kg} \mathrm{~m}^{-1} \mathrm{~s}^{-1}$ and is constant afterwards for more readability).
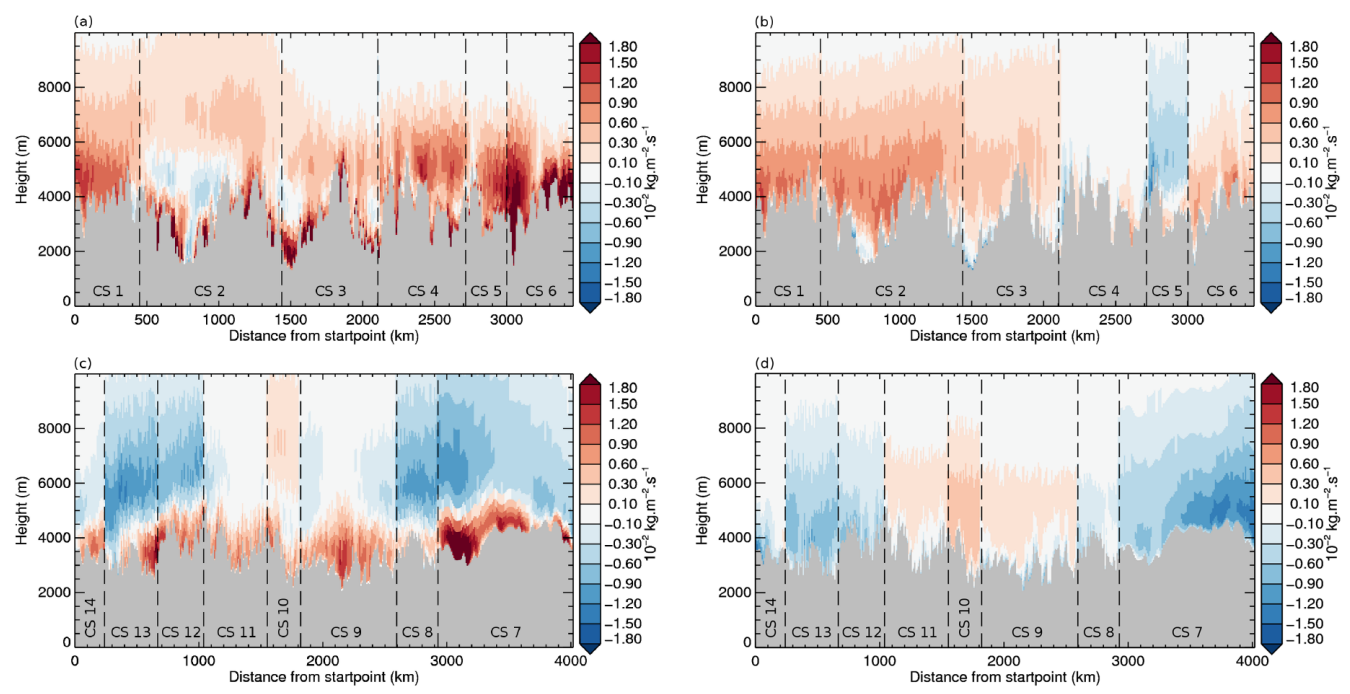

Figure 9. Decadal average of the atmospheric water transport $\left(10^{-2} \mathrm{~kg} \mathrm{~m}^{-2} \mathrm{~s}^{-1}\right)$ for cross sections 1-6 (a and b) (from left to right, dashed lines indicate border between the cross sections) in July (a) and January (b), and for cross sections 14-7 (c \& d) in July (c) and January (d) for HAR10. Red colours denote transport towards the TP, while blue colours indicate transport away from the TP. The underlying topography is represented in grey. 
itation patterns and affects a region with a higher population density. We see an anticyclonic circulation of the WV transport in the levels 10 and 12 (and in between). The transported amount is nearly as high as the WV transport associated with the ISM along the southern slopes of the Himalayas. However, if we look at the precipitation patterns, we see that there is a precipitation minimum in this region (Fig. 6). The development of deep convection is suppressed by subsidence. In the lower levels, the heat low over Pakistan (Bollasina and Nigam, 2010) is visible in the transport patterns (Fig. 8) and in the $10 \mathrm{~m}$ wind field (Fig. 6). Saeed et al. (2010) point out that the heat low over Pakistan connects the mid-latitude wave train with the Indian summer monsoon. In the surrounding region where we do not see this anticyclonic movement in the levels above the boundary layer, the large amounts of transported WV result in high amounts of precipitation. These results can provide an indication of the processes, which lead to the risk of droughts and floods (e.g. in July 2010) in Pakistan, as already analysed by Galarneau et al. (2012)

\subsection{Transport towards the Tibetan Plateau through its borders}

We calculated the WV input towards the TP through its borders (Fig. 9 and Table 1). For the southern boundary cross sections (CS 2-6) the highest transport amounts occur in summer (Fig. 9a) in the lower layers and decreases with increasing height. The largest fluxes occur in the regions where the elevation is lower compared to the direct surroundings, in the large meridionally orientated valleys (eastern Himalayas, in the region of the Brahmaputra channel). There, the areas of lower elevation are wider and the AWT from the Indian Ocean hits the mountain ranges directly from the south.

The AWT from the TP to the south is negligible in summer (Fig. 9a). It occurs mainly in CS 2 and a little in CS 3. This kind of recirculation may reflect northward transport. It takes place in the lower levels above a layer with high northward transport amounts. In winter (Fig. 9b), AWT is lower but the input of atmospheric moisture is still dominant.

The AWT through the western boundary (CS 1) (Fig. 9a and $b$, and Table 1) is higher in winter than in summer, as it is for CS 2 in the westernmost region of the Himalayas. These regions are dominated by atmospheric water input by extra-tropical air masses, transported to this region by the westerlies. In sum, the AWT in CS 2 is still almost as high as the AWT in CS 6. CS 6 contains the Brahmaputra Channel, which is often referred to as one of the main input channels for atmospheric moisture (Tian et al., 2001).

Table 1 shows the monthly decadal average of AWT input to the TP through the individual cross sections converted to a theoretical equivalent precipitation amount on the inner TP. We picked CS 1 and CS 6 for a closer comparison because CS 6 includes the Brahmaputra Channel and CS 1 is the western boundary, and they are of the same length. From
November to April the transport through the western boundary (CS 1) is distinctly greater than that through CS 6. From May to October CS 6 shows higher transport amounts, but the differences are less than for the wintertime. In July the input of CS 1 is $90.47 \%$ that of CS 6 . This means that the input through the western boundary is around $90 \%$ of the transport through the Brahmaputra Channel region. This is the month where the differences are smallest. We can see that for almost every month, CS 2-3 exhibits the largest input amounts. AWT through this cross section is controlled not only by the ISM but also by the southern branch of the mid-latitude westerlies.

The cross section for the eastern boundary (CS 7) shows that the TP is a source of atmospheric water for the downstream regions east of the TP for all months (Table 1 and Fig. 9c and d). In January, there is only eastward transport through the eastern boundary (Fig. 9d). In the other months (not shown except for July, Fig. 9c), we find additionally transport towards the TP in the lower layers near the surface. The transport towards the TP through eastern cross section has its peak in July (Fig. 9c) in the northern parts of the boundary where the elevation is distinctly lower than in the southern parts. Above this region, there is still eastward AWT away from the TP. However, if we look at the total of the AWT amount through the eastern boundary, we see that the transport from the plateau towards the east is also dominant in summer.

The transport through the northern boundary (CS 14-8) towards the TP (input) is lower than from the west and south in January and July (Fig. 9d and c, Table 1), although the circulation is directed to the boundary of the TP especially in summer. There, we find a strong gradient in altitude and fewer passages through which the atmospheric water could enter the TP than in the Himalayas. For the westernmost northern cross sections (14-12) the transport from the TP to the north is dominant. The reason for this is the north-eastward transport in the western TP, which also explains the lower transport amounts towards the TP. The AWT within the northern branch of the westerlies north of the TP is blocked by the high-altitude TP. AWT then follows the northern border of the TP to the east, where the elevation is lower in some regions (CS 9-11), e.g. at the border to the Qaidam Basin (CS 9). There, the input of atmospheric water to the TP is dominant for all months and the maximum input takes place in spring. AWT from the north to the Qaidam Basin is also visible in Fig. 4 for all months. This transport takes place in the lower layers of the atmosphere. The transport from the plateau northwards has its peak at the easternmost northern CS (CS 8) in July, August and September, when the TP can provide large amounts of atmospheric water, as shown in Sect. 3.2.1 in Fig. 4. 


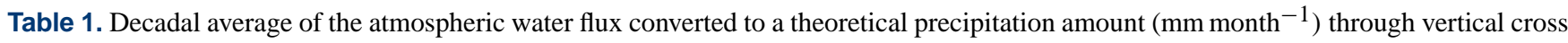
sections $(1,2-3,4-5,6,7,8,9,10-11,12-14)$ and standard deviations (SD) for HAR10 (positive values denote transport towards the TP and negative values denote transport away from the TP). Decadal average of the precipitation ( $\mathrm{mm} \mathrm{month}^{-1}$ ) and its standard deviation (SD) on the inner TP and of the contribution (\%) of the atmospheric water flux to the precipitation for HAR 10.

\begin{tabular}{|c|c|c|c|c|c|c|c|c|c|c|c|c|}
\hline $\mathrm{CS}$ & 1 & $2-3$ & $4-5$ & 6 & 7 & 8 & 9 & $10-11$ & $12-14$ & $1-14$ & & \\
\hline Month & West & SW 1-2 & South 1-2 & Brahmaputra & East & North-east & Qaidam & NW 5-4 & NW 3-1 & Sum & $\begin{array}{r}\text { Inner TP } \\
\text { precipitation }\end{array}$ & Ratio \\
\hline 01 & 12.8 & 41.2 & -5.0 & 5.9 & -34.0 & -2.1 & 3.7 & 7.2 & -17.7 & 12.1 & 22.9 & $52.6 \%$ \\
\hline 02 & 15.8 & 47.4 & -4.7 & 5.4 & -31.5 & -2.6 & 3.8 & 7.5 & -21.1 & 20.0 & 33.5 & $59.7 \%$ \\
\hline 03 & 19.8 & 35.4 & -6.0 & 7.6 & -37.8 & -2.9 & 8.1 & 11.1 & -23.9 & 11.5 & 33.9 & $33.9 \%$ \\
\hline 04 & 17.8 & 33.4 & -4.7 & 9.1 & -36.2 & -3.3 & 9.5 & 10.6 & -22.8 & 13.4 & 42.7 & $31.4 \%$ \\
\hline 05 & 17.1 & 21.5 & 9.1 & 21.3 & -44.3 & -5.6 & 8.5 & 10.4 & -19.1 & 18.9 & 55.3 & $34.2 \%$ \\
\hline 06 & 12.2 & 26.4 & 18.6 & 22.2 & -42.4 & -6.4 & 9.1 & 7.7 & -14.5 & 32.9 & 72.3 & $45.5 \%$ \\
\hline 07 & 14.9 & 34.4 & 24.3 & 16.5 & -19.4 & -12.2 & 4.2 & 5.3 & -22.5 & 45.4 & 98.0 & $46.4 \%$ \\
\hline 08 & 11.7 & 33.7 & 22.5 & 16.1 & -22.9 & -12.7 & 6.2 & 6.8 & -22.6 & 38.8 & 91.8 & $42.2 \%$ \\
\hline 09 & 12.3 & 44.0 & 20.3 & 19.0 & -55.1 & -11.3 & 2.4 & 5.1 & -21.9 & 14.8 & 57.6 & $25.7 \%$ \\
\hline 10 & 15.4 & 21.3 & 9.6 & 18.4 & -56.3 & -5.0 & 3.6 & 6.2 & -17.3 & -4.1 & 23.6 & $-17.5 \%$ \\
\hline 11 & 16.9 & 24.4 & -5.9 & 4.9 & -35.5 & -2.5 & 5.8 & 9.4 & -20.5 & -3.0 & 11.9 & $-25.2 \%$ \\
\hline 12 & 15.0 & 36.5 & -6.6 & 3.3 & -34.2 & -2.1 & 4.9 & 8.9 & -20.5 & 5.3 & 15.8 & $33.7 \%$ \\
\hline $\begin{array}{l}\text { Sum } \\
\left(\mathrm{mm} \mathrm{yr}^{-1}\right)\end{array}$ & 181.6 & 399.6 & 71.7 & 149.8 & -449.8 & -68.8 & 70.1 & 96.2 & -244.2 & 206.0 & 559.2 & $\begin{array}{r}(36.8 \pm \\
6.3) \%\end{array}$ \\
\hline $\begin{array}{l}\text { SD } \\
\left(\mathrm{mm} \mathrm{yr}^{-1}\right)\end{array}$ & 59.4 & 47.6 & 15.5 & 22.1 & 44.1 & 8.4 & 12.7 & 12.8 & 24.5 & 42.6 & 77.1 & \\
\hline $\begin{array}{l}\mathrm{SD} \\
(\%)\end{array}$ & $32.7 \%$ & $11.9 \%$ & $21.6 \%$ & $14.8 \%$ & $9.8 \%$ & $12.3 \%$ & $18.1 \%$ & $13.3 \%$ & $10.0 \%$ & $20.7 \%$ & $13.8 \%$ & \\
\hline
\end{tabular}

Table 2. The same as Table 1 but for HAR30.

\begin{tabular}{|c|c|c|c|c|c|c|c|c|c|c|c|c|}
\hline $\mathrm{CS}$ & 1 & $2-3$ & $4-5$ & 6 & 7 & 8 & 9 & $10-11$ & $12-14$ & $1-14$ & & \\
\hline Month & West & SW 1-2 & South 1-2 & Brahmaputra & East & North-east & Qaidam & NW 5-4 & NW 3-1 & Sum & $\begin{array}{r}\text { Inner TP } \\
\text { precipitation }\end{array}$ & Ratio \\
\hline 01 & 13.6 & 43.1 & -7.9 & 6.4 & -35.9 & -2.6 & 3.9 & 7.6 & -19.9 & 8.3 & 24.3 & $34.0 \%$ \\
\hline 02 & 16.7 & 49.8 & -7.4 & 6.1 & -33.7 & -3.2 & 4.1 & 8.1 & -23.8 & 16.8 & 35.7 & $47.0 \%$ \\
\hline 03 & 21.5 & 36.9 & -9.1 & 9.3 & -41.1 & -3.4 & 8.6 & 12.1 & -27.5 & 7.3 & 36.7 & $19.9 \%$ \\
\hline 04 & 19.6 & 35.2 & -8.3 & 11.1 & -39.5 & -3.7 & 10.1 & 11.3 & -26.6 & 9.2 & 46.0 & $20.0 \%$ \\
\hline 05 & 19.0 & 21.4 & 7.5 & 23.3 & -47.3 & -5.9 & 9.2 & 10.9 & -22.3 & 15.9 & 60.0 & $26.5 \%$ \\
\hline 06 & 13.4 & 25.1 & 20.1 & 23.2 & -47.1 & -6.5 & 10.1 & 7.5 & -16.1 & 29.8 & 76.2 & $39.1 \%$ \\
\hline 07 & 16.2 & 32.2 & 27.6 & 14.1 & -24.0 & -12.6 & 4.9 & 3.9 & -24.0 & 48.3 & 98.8 & $38.8 \%$ \\
\hline 08 & 12.2 & 32.1 & 25.5 & 14.0 & -27.3 & -13.4 & 7.0 & 5.2 & -23.7 & 31.6 & 91.8 & $34.5 \%$ \\
\hline 09 & 13.4 & 43.2 & 22.8 & 19.3 & -60.7 & -12.1 & 2.9 & 4.5 & -24.2 & 9.1 & 58.4 & $15.5 \%$ \\
\hline 10 & 17.1 & 20.2 & 8.6 & 19.7 & -59.2 & -5.8 & 4.0 & 6.8 & -20.3 & -8.9 & 25.1 & $-35.6 \%$ \\
\hline 11 & 18.4 & 24.5 & -9.6 & 5.0 & -37.1 & -3.1 & 6.1 & 10.2 & -23.6 & -9.1 & 12.9 & $-71.1 \%$ \\
\hline 12 & 16.0 & 38.2 & -10.1 & 3.3 & -35.9 & -2.7 & 5.2 & 9.5 & -23.0 & 0.4 & 16.7 & $32.7 \%$ \\
\hline $\begin{array}{l}\text { Sum } \\
\left(\mathrm{mm} \mathrm{yr}^{-1}\right)\end{array}$ & 197.2 & 401.9 & 59.7 & 154.9 & -488.6 & -75.0 & 76.1 & 97.4 & -274.9 & 148.7 & 582.5 & $\begin{array}{r}(25.5 \pm \\
7.4) \%\end{array}$ \\
\hline $\begin{array}{l}\text { SD } \\
\left(\mathrm{mm} \mathrm{yr}^{-1}\right)\end{array}$ & 25.4 & 53.2 & 18.3 & 23.5 & 212.7 & 9.4 & 13.8 & 13.5 & 27.8 & 47.4 & 81.0 & \\
\hline & $12.9 \%$ & $13.2 \%$ & $30.6 \%$ & $15.2 \%$ & $43.5 \%$ & $12.5 \%$ & $18.1 \%$ & $13.9 \%$ & $10.1 \%$ & $31.9 \%$ & $13.9 \%$ & \\
\hline
\end{tabular}

\subsection{Budget}

Since we analysed AWT transport in and to the TP and quantified the input and output, the question arises of which amount of precipitation falling on the inner TP results from external moisture supply and which amount is provided by the TP itself from local sources and moisture recycling.

Table 1 displays the monthly decadal average of AWT through the individual cross sections and the sum for all cross sections, the precipitation falling on the inner TP and the ra- tios between them. To make the comparison with the precipitation easier, we converted the net atmospheric water input to a theoretical precipitation equivalent $\left(\mathrm{mm} \mathrm{month} \mathrm{h}^{-1}\right)$. We obtain an annual mean AWT input of $206.0 \mathrm{~mm} \mathrm{yr}^{-1}$ for HAR10. For the mean annual precipitation falling on the inner TP, a value of $559.2 \mathrm{~mm} \mathrm{yr}^{-1}$ results. The ratio of net input of atmospheric water to the precipitation falling on the inner TP reveals that, on average, AWT through the borders accounts for $36.8 \%$ of the precipitation during the year. Ac- 
cording to this, the remaining $63.2 \%$ of atmospheric water needed for precipitation must be provided by the TP itself. This moisture supply probably takes place via moisture recycling from local sources, e.g. evaporation from numerous large lakes, soil moisture, the active layer of permafrost, snow melt and glacier run-off. The ratio is highest in winter when the TP cannot provide moisture for precipitation by itself, followed by summer, where the largest net input occurs. In October and November the ratio is negative, which means that the TP provides more moisture than it receives from external sources. These are the 2 months where the output of moisture from the TP is larger than the input; this is possible because the moisture imported to the TP in summer is available for export in autumn. On a monthly basis, there is certainly a time lag between the moisture entrance and the precipitation, making the analysis of the monthly ratios difficult. The standard deviations for HAR10 (HAR30) in Table 1 (2) show that the atmospheric water input varies more between the years than the precipitation falling on the TP. This implies that the evaporation from local sources stabilises the precipitation falling on the inner TP.

\section{Discussion}

\subsection{General discussion of results}

The main WV input to the TP takes place through the southern and western boundaries, confirming the results of Feng and Zhou (2012), even if their western boundary is further east. The WV entering the TP through the eastern part of the southern boundary originates from the monsoonal air masses, while the WV entering the TP through the western boundary originates in the mid-latitude westerlies. The relatively high input through the western boundary shows that the westerlies are not fully blocked by the TP and not all moisture transported with them is redirected north or south. The magnitude of this WV input is similar to that of the input through the Brahmaputra channel. This agrees with the findings of Mölg et al. (2013), who found that the westerlies play a role for precipitation and glacier mass balance in summer also, and they challenged the assumption that the westerlies contribute moisture only in winter or just in the northernmost parts of the TP in summer (Hren et al., 2009; Tian et al., 2007). Our results show that there is direct atmospheric water transport through the western boundary by the mid-latitude westerlies in summer, which shoes that the westerlies are not fully blocked by the TP. The westerlies also contribute moisture to the TP through valleys in the western parts of the southern boundary by the southern branch of the westerlies. This implies that moisture entering the TP from the south-west can be transported there either by the westerlies or the monsoon, depending on the how far these systems extend eastward or westward along the southern slopes of the Himalayas, respectively. The examination of this structure will be the subject of a subsequent study. The main WV output from the TP takes place through the eastern border, as also found by Feng and Zhou (2012). The TP is a source of moisture for the downstream regions in the east throughout the year like the Yangtze River valley in China, agreeing the results from Chen et al. (2012) and Luo and Yanai (1983), that the TP contributes precipitation to its downstream areas in summer. Thus we can confirm the importance of the findings from Bin et al. (2013), Xu et al. (2011) and Chen et al. (2012), who called the TP a transfer or re-channel platform of moisture for the downstream regions in East Asia.

In our study, we could not find any contribution of the East Asian Summer Monsoon to the WV transport towards the TP, although it has thus far been assumed to have an influence on the TP (Yao et al., 2012; Bolch et al., 2012). The WV transported from east to the TP in the lower levels in summer (CS 7, Fig. 9c), also detected by Luo and Yanai (1983) and Feng and Zhou (2012), is not transported to this region by the East Asian Monsoon flow but by the eastern branch of the Indian summer monsoon flow. This is clear if we look at the transport patterns for HAR30 (Fig. 3). It is interesting that the HAR WV flux has a stronger westward component east of the TP than ERA-Interim (Fig. 2c) and still does not show any transport from east to west in the climate mean state. Since we focus on the mean climatology during our period of investigation, we cannot exclude the contribution of moisture from the East Asian summer monsoon (EASM) to the TP for single years or events, but at the same time we expect it to be visible in the mean if it is significant. Our hypothesis is that the transient weather systems could bring moisture from the east to the TP; however they are not visible in the means. It will be the goal of a future study to examine such weather systems in detail.

Prior studies focused on the WV transport and did not consider the CP flux. The assumption so far was that the CP transport is so small compared to the WV flux, that it does not have a significant influence on the atmospheric moisture transport. Our results show that the contribution of the CP flux to the entire AWT is not negligible in winter in the Pamir and Karakoram ranges (the western and south-western border of the TP), where it contributes up to $25 \%$ of the entire AWT. The fact that the CP transport plays a role in the Karakoram and western Himalayas, the regions which are controlled mainly by the westerlies, lets us conclude that in this region moisture advection presumably plays a strong role. The horizontal motion is dominant in advective processes towards convection where the vertical motion is dominant. This leads to the fact that clouds developed in advective processes, for example frontal processes, can be transported further away from their origin than convective clouds.

The moisture supply from external sources provides around $36.8 \%$ of the atmospheric water needed to produce the mean annual precipitation on the inner TP while the remaining part originates from the TP itself by local moisture recycling. These results highlights the importance of local moisture recycling as already emphasized by Kurita and Ya- 
mada (2008), Joswiak et al. (2013) and Chen et al. (2012). For the northern Tibetan Plateau, Yang et al. (2006) detected that $32.06 \%$ of the precipitation is formed by water vapour from ocean air mass and $46.86 \%$ is formed by water vapour evaporated from local sources. They found that at least $21.8 \%$ of the precipitation is formed by water vapour evaporated on the way and then transported by the monsoon circulation. Yang et al. (2007) also showed that for two flat observation sites in the central eastern part of the TP, the evaporation is 73 and $58 \%$ of the precipitation amount. This is in a good agreement with our results that $63.3 \%$ is provided by local moisture recycling. This moisture is provided by evaporation from numerous large lakes, soil moisture, the active layer of permafrost, snow melt and glacier run-off. The question arises over what will happen with the atmospheric water, which is transported to the TP. Does it remain in the $\mathrm{TP}$ or is it lost as run-off. Could this moisture input be an explanation for the observed lake level rises?

The comparison of the net atmospheric water input to the TP through the cross sections, the precipitation falling on the inner TP and the ratio between them for HAR10 (Table 1) and HAR30 (Table 2) show that the different horizontal resolutions result in differences between the two data sets. On an annual basis, the different horizontal resolutions result in an AWT input difference of $57.3 \mathrm{~mm} \mathrm{yr}^{-1}$ and a precipitation difference on the inner TP of $23.3 \mathrm{~mm} \mathrm{yr}^{-1}$, where HAR30 has the lower AWT input but the higher precipitation amount. This leads to a difference of 11.3 percentage points in the ratio of AWT to precipitation between the HAR10 (36.8\%) and HAR30 (25.5\%) data sets. Nevertheless, HAR30 has, for almost every cross section and month, higher transport amounts for both input and output. Due to the fact that the output values are also higher, the annual net input for HAR30 is lower than for HAR10. On an annual basis HAR30 shows just three-fourths of the HAR10 AWT input. A possible explanation for lower transport amounts for individual cross sections in HAR10 could be that the higher horizontal resolution is overridden by higher orographic barriers due to better representation of the topography. Shi et al. (2008) showed that a higher horizontal resolution and more realistic representation of the topography is important for the development of disturbances leading to precipitation events in the downstream regions of the TP like the Yangtze River valley. Our study shows that for a quantification of AWT and the spatiotemporal detection of its major pathways and sources it is important to examine the complex topography of high Asia with high spatial resolution.

\subsection{Sources of uncertainty}

The uncertainty of the results depends on the accuracy of the data itself, the position of the cross sections used to calculate the budget and the vertical resolution of the data set.

Maussion et al. (2014) compared HAR precipitation with rain-gauge observations and the TRMM precipitation prod- ucts 3B42 (daily), 3B43 (monthly) and 2B31 (higher resolution). They found an improvement when increasing the horizontal resolution from 30 to $10 \mathrm{~km}$ in comparison to the gauges. A slight positive bias could be detected against the same stations $\left(0.17 \mathrm{~mm} \mathrm{day}^{-1}\right.$ for HAR 10 and monthly precipitation values, their Fig. 3), comparable to that of TRMM 3B43 $\left(0.26 \mathrm{~mm} \mathrm{day}^{-1}\right)$. Converted to annual values $\left(62 \mathrm{~mm} \mathrm{yr}^{-1}\right)$ and compared to the value of HAR precipitation averaged over the inner TP $\left(559 \mathrm{~mm} \mathrm{yr}^{-1}\right)$, this bias remains significant. In a simple first-order approach, by assuming this bias to be constant over the region (and assuming no rain gauge undercatch), this would increase the part of moisture needed for precipitation coming from the outer TP from 36.8 to $41.4 \%$.

To determine if the position of the cross sections has an influence on our results, we replicated our budget analyses with the cross sections moved around $60 \mathrm{~km}$ towards the centre of the TP for the HAR10 data set. This results in new budget values for net atmospheric water input of $202.6 \mathrm{~mm} \mathrm{yr}^{-1}$ (206.0 $\mathrm{mm} \mathrm{yr}^{-1}$ with the old cross sections), and $506.3 \mathrm{~mm} \mathrm{yr}^{-1}\left(559.2 \mathrm{~mm} \mathrm{yr}^{-1}\right)$ precipitation falling on the inner TP. This result in a change of the percentage from $36.8 \%$ (found for the original position of the cross sections) to $40 \%$. This is caused mainly by a change of the precipitation amount of $-52.9 \mathrm{~mm} \mathrm{yr}^{-1}$, while the atmospheric water input is nearly the same $\left(-3.4 \mathrm{~mm} \mathrm{yr}^{-1}\right)$. This change is smaller than the standard deviation $(6.3 \%)$ of this ratio.

We analysed if the vertical resolution could have an influence on precipitation and moisture transport by creating a new series of simulations for the entire year of 2010 , whereby we increased the number of vertical levels from 28 to 36 (all other settings kept unchanged). Precipitation patterns in the HAR10 domain remain very similar. Large absolute differences are found in the monsoonal affected regions south of the TP and the Himalayas. The largest relative differences occur in regions with very low precipitation rates, in the arid regions (e.g. Tarim Basin) north of the TP. The amounts and patterns of the vertically integrated atmospheric water transport match well with one another, relative differences are around $\pm 5 \%$ in the TP and only slightly higher in small regions south and north of the TP. The computation of the water budget for the year 2010 for 36 (28) vertical levels results in a net input of atmospheric water of $191.9 \mathrm{~mm} \mathrm{yr}^{-1}$ $\left(195.2 \mathrm{~mm} \mathrm{yr}^{-1}\right)$, with $623.3 \mathrm{~mm} \mathrm{yr}^{-1}\left(621.8 \mathrm{~mm} \mathrm{yr}^{-1}\right)$ precipitation falling on the inner TP and an annual proportion of $30.8 \%(31.4 \%)$ for 2010 . This shows that the results obtained with 28 vertical levels are reliable.

There is no other possible way to estimate the uncertainty of the computed fluxes than the rough comparison of ERAInterim provided in Sect. 3.1. Certainly, the choice of the model set-up and the reinitialization strategy also influence our results. Put together, these uncertainties are not negligible but there is no indication that our core conclusions are significantly affected. 
Due to the temporal averaging of the model results to monthly means, we ascertain the mean climatology, but lose the ability to analyse the data process based. The processes regarding the interplay of atmospheric water transport and precipitation will be the subject of a subsequent study at a higher temporal resolution (e.g. daily).

\section{Conclusions}

The TP experiences high precipitation variability leading to dry spells and droughts, as well as to severe snow- and rainfall events and subsequent floods. However, there are strong differences between regions and seasons which are not yet well understood on present-day climate conditions, making statements for past and future climates highly speculative. Therefore, in another study, we will analyse if there are significant differences in the AWT patterns in wet and dry years to find out whether the extremes are influenced by changes in atmospheric circulations or just in a change of the transported amount of atmospheric water. These results could then be compared with the results of Lu et al. (2014), who analysed the differences in the atmospheric circulation for wet and dry monsoon seasons of nearly the same period (20002010) using coarser-resolution data sets. Large-scale teleconnections, such as the influence of the North Atlantic Oscillation (NAO) mode during wet and dry periods, have been analysed for longer periods by, e.g. Liu and Yin (2001) and Bothe et al. (2009, 2011). An examination of the AWT patterns in the HAR during periods with positive or negative NAO index could be used to potentially reconfirm their findings using higher-resolution data. Interesting regional features, such as the large amount of atmospheric water over the dry Qaidam Basin, which does not result in precipitation, need to be studied in detail by analysing the reasons for precipitation suppression. Dust particles originating in the arid regions could play a role in precipitation suppression (Han et al., 2009).

Our first water budget estimate reveals that local moisture recycling is an important factor and provides more moisture than the input from external sources (on average $60 \%$ versus $40 \%$ ). Moisture recycling has to be studied more in detail in the future to gain a better understanding of the water cycle in the TP. It would be interesting to analyse if and how the atmospheric water stored in snow in winter contributes to the atmospheric water transport and precipitation of the following warm season. Due to this storage term, the westerlies could play an even greater role in the hydrological cycle of some regions of the TP in summer. It is difficult to clearly differentiate between moisture provided by the large-scale circulations (mid-latitude westerlies and monsoon systems) or local moisture recycling because, for example, monsoonal moisture could reach the north-eastern parts of the TP via multiple moisture recycling as mentioned by Yang et al. (2006). Also, the mixing of water vapour sources as seen in the ex- amination of the vertical structure of the transport shows that the general question of where the moisture comes from often cannot be answered by naming only one source. This can make the identification of moisture sources using isotope signals difficult. Therefore, the part of the atmospheric column where the precipitation actually forms has to be identified in addition to the development of a more in-depth analysis of the atmospheric water transport fluxes on individual levels. Additionally the other components of the water balance, e.g. evaporation and run-off, should be considered in further studies.

Acknowledgements. This work was supported by the German Federal Ministry of Education and Research (BMBF) Programme, Central Asia - Monsoon Dynamics and Geo-Ecosystems (CAME), within the WET project (Variability and Trends in Water Balance Components of Benchmark Drainage Basins on the Tibetan Plateau) under the code 03G0804A and by the German Research Foundation (DFG) Priority Programme 1372, Tibetan Plateau: Formation - Climate - Ecosystems, within the DynRG-TiP (Dynamic Response of Glaciers on the Tibetan Plateau to Climate Change) project under the codes SCHE 750/4-1, SCHE 750/4-2 and SCHE 750/4-3. The author F. Maussion acknowledges support by the Austrian Science Fund (FWF project P22443-N21). We would like to thank Oliver Bothe and a further anonymous referee for their thoughtful comments and critique.

Edited by: M. Werner

\section{References}

An, Z., Colman, S. M., Zhou, W., Li, X., Brown, E. T., Jull, A. J. T., Cai, Y., Huang, Y., Lu, X., Chang, H., Song, Y., Sun, Y., Xu, H., Liu, W., Jin, Z., Liu, X., Cheng, P., Liu, Y., Ai, L., Li, X., Liu, X., Yan, L., Shi, Z., Wang, X., Wu, F., Qiang, X., Dong, J., $\mathrm{Lu}, \mathrm{F}$., and $\mathrm{Xu}, \mathrm{X}$. .: Interplay between the Westerlies and Asian monsoon recorded in Lake Qinghai sediments since 32 ka., Sci. Rep., 2, 619, doi:10.1038/srep00619, 2012.

Araguás-Araguás, L., Froehlich, K., and Rozanski, K.: Stable isotope composition of precipitation over southeast Asia, J. Geophys. Res., 103, 28721-28742, doi:10.1029/98JD02582, 1998.

Bin, C., Xiang-De, X., and Tianliang, Z.: Main moisture sources affecting lower Yangtze River Basin in boreal summers during 2004-2009, Int. J. Climatol., 33, 1035-1046, doi:10.1002/joc.3495, 2013.

Bolch, T., Kulkarni, A., Kääb, A., Huggel, C., Paul, F., Cogley, J. G., Frey, H., Kargel, J. S., Fujita, K., Scheel, M., Bajracharya, S., and Stoffel, M.: The state and fate of Himalayan glaciers, Science, 336, 310-314, doi:10.1126/science.1215828, 2012.

Bollasina, M. and Nigam, S.: The summertime "heat" low over Pakistan/northwestern India: evolution and origin, Clim. Dynam., 37, 957-970, doi:10.1007/s00382-010-0879-y, 2010.

Bookhagen, B. and Burbank, D. W.: Toward a complete Himalayan hydrological budget: Spatiotemporal distribution of snowmelt and rainfall and their impact on river discharge, J. Geophys. Res., 115, F03019, doi:10.1029/2009JF001426, 2010. 
Bothe, O., Fraedrich, K., and Zhu, X.: The large-scale circulations and summer drought and wetness on the Tibetan Plateau, Int. J. Climatol., 30, 844-855, doi:10.1002/joc.1946, 2009.

Bothe, O., Fraedrich, K., and Zhu, X.: Large-scale circulations and Tibetan Plateau summer drought and wetness in a high-resolution climate model. Int. J. Climatol., 31, 832-846, doi:10.1002/joc.2124, 2011.

Chen, B., Xu, X.-D., Yang, S., and Zhang, W.: On the origin and destination of atmospheric moisture and air mass over the Tibetan Plateau, Theor. Appl. Climatol., 110, 423-435, doi:10.1007/s00704-012-0641-y, 2012.

Dee, D. P., Uppala, S. M., Simmons, a. J., Berrisford, P., Poli, P., Kobayashi, S., Andrae, U., Balmaseda, M. a., Balsamo, G., Bauer, P., Bechtold, P., Beljaars, a. C. M., van de Berg, L., Bidlot, J., Bormann, N., Delsol, C., Dragani, R., Fuentes, M., Geer, a. J., Haimberger, L., Healy, S. B., Hersbach, H., Hólm, E. V., Isaksen, L., Kållberg, P., Köhler, M., Matricardi, M., McNally, a. P., Monge-Sanz, B. M., Morcrette, J.-J., Park, B.-K., Peubey, C., de Rosnay, P., Tavolato, C., Thépaut, J.-N., and Vitart, F.: The ERA-Interim reanalysis: configuration and performance of the data assimilation system, Q. J. Roy. Meteorol. Soc., 137, 553597, doi:10.1002/qj.828, 2011.

Feng, L. and Zhou, T.: Water vapor transport for summer precipitation over the Tibetan Plateau: Multidata set analysis, J. Geophys. Res.-Atmos., 117, D20114, doi:10.1029/2011JD017012, 2012.

Flohn, H.: Contributions to a meteorology of the Tibetan highlands. Atmospheric Science Paper No. 130, Department of Atmosphere Science, Colorado State University: Colorado, 1968.

Galarneau, T. J., Hamill, T. M., Dole, R. M., and Perlwitz, J.: A Multiscale Analysis of the Extreme Weather Events over Western Russia and Northern Pakistan during July 2010, Mon. Weather Rev., 140, 1639-1664, doi:10.1175/MWR-D-11-00191.1, 2012.

Gao, Y., Cuo, L., and Zhang, Y.: Changes in Moisture Flux over the Tibetan Plateau during 1979-2011 and Possible Mechanisms, J. Climate, 27, 1876-1893, doi:10.1175/JCLI-D-13-00321.1, 2014.

Günther, F., Mügler, I., Mäusbacher, R., Daut, G., Leopold, K., Gerstmann, U. C., Xu, B., Yao, T., and Gleixner, G.: Response of $\mathrm{dD}$ values of sedimentary $\mathrm{n}$-alkanes to variations in source water isotope signals and climate proxies at lake Nam Co , Tibetan Plateau, Quaternary Int., 236, 82-90, doi:10.1016/j.quaint.2010.12.006, 2011.

Guenther, F., Aichner, B., Siegwolf, R., Xu, B., Yao, T., and Gleixner, G.: A synthesis of hydrogen isotope variability and its hydrological significance at the Qinghai-Tibetan Plateau, Quaternary Int., 313-314, 3-16, doi:10.1016/j.quaint.2013.07.013, 2013

Han, Y., Fang, X., Zhao, T., Bai, H., Kang, S., and Song, L.: Suppression of precipitation by dust particles originated in the Tibetan Plateau, Atmos. Environ., 43, 568-574, doi:10.1016/j.atmosenv.2008.10.018, 2009.

Hren, M. T., Bookhagen, B., Blisniuk, P. M., Booth, A. L., and Chamberlain, C. P.: $\delta 18 \mathrm{O}$ and $\delta \mathrm{D}$ of streamwaters across the Himalaya and Tibetan Plateau: Implications for moisture sources and paleoelevation reconstructions, Earth Planet. Sci. Lett., 288, 20-32, doi:10.1016/j.epsl.2009.08.041, 2009.

Immerzeel, W. W., van Beek, L. P. H., and Bierkens, M. F. P.: Climate change will affect the Asian water towers, Science, 328, 1382-1385, doi:10.1126/science.1183188, 2010.
Immerzeel, W. W., Pellicciotti, F., and Bierkens, M.: Rising river flows throughout the twenty-first century in two Himalayan glacierized watersheds, Nat. Geosci., 6, 742-745, doi:10.1038/ngeo1896, 2013.

Joswiak, D. R., Yao, T., Wu, G., Tian, L., and Xu, B.: Icecore evidence of westerly and monsoon moisture contributions in the central Tibetan Plateau, J. Glaciol., 59, 56-66, doi:10.3189/2013JoG12J035, 2013.

Kang, S., Qin, D., Ren, J., Zhang, Y., Kaspari, S., Mayewski, P. A., and Hou, S.: Annual Accumulation in the Mt. Nyainqentanglha Ice Core, Southern Tibetan Plateau, China: Relationships To Atmospheric Circulation over Asia, Arctic, Antarct. Alp. Res., 39, 663-670, doi:10.1657/1523-0430(07503)[KANG]2.0.CO;2, 2007.

Kurita, N. and Yamada, H.: The Role of Local Moisture Recycling Evaluated Using Stable Isotope Data from over the Middle of the Tibetan Plateau during the Monsoon Season, J. Hydrometeorol., 9, 760-775, doi:10.1175/2007JHM945.1, 2008.

Liu, J., Kang, S., Gong, T., and Lu, A.: Growth of a high-elevation large inland lake, associated with climate change and permafrost degradation in Tibet, Hydrol. Earth Syst. Sci., 14, 481-489, doi:10.5194/hess-14-481-2010, 2010.

Liu, X. and Yin, Z.-Y.: Spatial and Temporal Variation of Summer Precipitation over the Eastern Tibetan Plateau and the North Atlantic Oscillation, J. Climate, 14, 2896-2909, doi:10.1175/15200442(2001)014, 2001.

Lu, N., Qin, J., Gao, Y., Yang, K., Trenberth, K. E., Gehne, M., and Zhu, Y.: Trends and variability in atmospheric precipitable water over the Tibetan Plateau for 2000-2010, Int. J. Climatol., doi:10.1002/joc.4064, in press, 2014.

Luo, H. and Yanai, M.: The large-scale circulation and heat sources over the Tibetan Plateau and surrounding areas during the early summer of 1979. Part I: Precipitation and kinematic, Mon. Weather Rev., 111, 922-944, doi:10.1175/15200493(1983)111<0922:TLSCAH>2.0.CO;2, 1983.

Maussion, F., Scherer, D., Finkelnburg, R., Richters, J., Yang, W., and Yao, T.: WRF simulation of a precipitation event over the Tibetan Plateau, China - an assessment using remote sensing and ground observations, Hydrol. Earth Syst. Sci., 15, 1795-1817, doi:10.5194/hess-15-1795-2011, 2011.

Maussion, F., Scherer, D., Mölg, T., Collier, E., Curio, J., and Finkelnburg, R.: Precipitation Seasonality and Variability over the Tibetan Plateau as Resolved by the High Asia Reanalysis*, J. Climate, 27, 1910-1927, doi:10.1175/JCLI-D-13-00282.1, 2014.

Mölg, T., Maussion, F., and Scherer, D.: Mid-latitude westerlies as a driver of glacier variability in monsoonal High Asia, Nat. Clim. Change, 4, 68-73, doi:10.1038/nclimate2055, 2013.

Saeed, S., Müller, W. A., Hagemann, S., and Jacob, D.: Circumglobal wave train and the summer monsoon over northwestern India and Pakistan: the explicit role of the surface heat low, Clim. Dynam., 37, 1045-1060, doi:10.1007/s00382-010-0888-x, 2010.

Schiemann, R., Lüthi, D., and Schär, C.: Seasonality and Interannual Variability of the Westerly Jet in the Tibetan Plateau Region*, J. Climate, 22, 2940-2957, doi:10.1175/2008JCLI2625.1, 2009.

Shi, X., Wang, Y., and Xu, X.: Effect of mesoscale topography over the Tibetan Plateau on summer precipitation in China: A regional model study, Geophys. Res. Lett., 35, L19707, doi:10.1029/2008GL034740, 2008. 
Simmonds, I., Bi, D., and Hope, P.: Atmospheric Water Vapor Flux and Its Association with Rainfall over China in Summer, J. Climate, 12, 1353-1367, 1999.

Skamarock, W. C. and Klemp, J. B.: A time-split nonhydrostatic atmospheric model for weather research and forecasting applications, J. Comput. Phys., 227, 3465-3485, doi:10.1016/j.jcp.2007.01.037, 2008.

Sugimoto, S., Ueno, K., and Sha, W.: Transportation of Water Vapor into the Tibetan Plateau in the Case of a Passing Synoptic-Scale Trough, J. Meteorol. Soc. Japan, 86, 935-949, doi:10.2151/jmsj.86.935, 2008.

Tian, L., Masson-Delmotte, V., Stievenard, M., Yao, T., and Jouzel, J.: Tibetan Plateau summer monsoon northward extent revealed by measurements of water stable isotopes, J. Geophys. Res., 106, 28081-28088, doi:10.1029/2001JD900186, 2001.

Tian, L., Yao, T., MacClune, K., White, J. W. C., Schilla, A., Vaughn, B., Vachon, R., and Ichiyanagi, K.: Stable isotopic variations in west China: A consideration of moisture sources, J. Geophys. Res., 112, D10112, doi:10.1029/2006JD007718, 2007.

Trenberth, K. E.: Atmospheric Moisture Recycling: Role of Advection and Local Evaporation, J. Climate, 12, 1368-1381, doi:10.1175/1520-0442(1999)012<1368:AMRROA>2.0.CO;2, 1999.

Webster, P., Magana, V. O., Palmer, T. N., Shukla, J., Tomas, R. A., Yanai, M., and Yasunari, T.: Monsoons: Processes, predictability, and the prospects for prediction, J. Geophys. Res., 103, 1445114510, doi:10.1029/97JC02719, 1998.

Xu, X., Lu, C., Shi, X., and Gao, S.: World water tower: An atmospheric perspective, Geophys. Res. Lett., 35, L20815, doi:10.1029/2008GL035867, 2008.
Xu, X., Shi, X., and Lu, C.: Theory and application for warning and prediction of disastrous weather downstream from the Tibetan Plateau (Vol. 1, 1-91), 2011.

Yang, K., Ye, B., Zhou, D., Wu, B., Foken, T., Qin, J., and Zhou, Z.: Response of hydrological cycle to recent climate changes in the Tibetan Plateau, Clim. Change, 109, 517-534, doi:10.1007/s10584-011-0099-4, 2011.

Yang, M., Yao, T., Wang, H., Tian, L., and Gou, X.: Estimating the criterion for determining water vapour sources of summer precipitation on the northern Tibetan Plateau, Hydrol. Process., 20, 505-513, doi:10.1002/hyp.5918, 2006.

Yang, M., Yao, T., Gou, X., and Tang, H.: Water recycling between the land surface and atmosphere on the Northern Tibetan Plateau-A case study at flat observation sites, Arc. Antarc. Alpine Res., 39, 694-698, 2007.

Yang, K., Wu, H., Qin, J., Lin, C., Tang, W., and Chen, Y.: Recent climate changes over the Tibetan Plateau and their impacts on energy and water cycle: A review, Global Planet. Change, 112, 79-91, doi:10.1016/j.gloplacha.2013.12.001, 2014.

Yao, T., Thompson, L., Yang, W., Yu, W., Gao, Y., Guo, X., Yang, X., Duan, K., Zhao, H., Xu, B., Pu, J., Lu, A., Xiang, Y., Kattel, D. B., and Joswiak, D.: Different glacier status with atmospheric circulations in Tibetan Plateau and surroundings, Nat. Clim. Change, 2, 663-667, doi:10.1038/nclimate1580, 2012.

Yao, T., Masson-Delmotte, V., Gao, J., Yu, W., Yang, X., Risi, C., Sturm, C., Werner, M., Zhao, H., He, Y., and Ren, W.: A review of climatic controls on $\delta 18$ o in precipitation over the Tibetan Plateau: Observations and simulations, Rev. Geophys., 51, 525548, doi:10.1002/rog.20023, 2013.

Zhang, Y., Wang, D., Zhai, P., Gu, G., and He, J.: Spatial Distributions and Seasonal Variations of Tropospheric Water Vapor Content over the Tibetan Plateau, J. Climate, 26, 5637-5654, doi:10.1175/JCLI-D-12-00574.1, 2013. 